\title{
THE OCULOCARDIAC REFLEX (DAGNINI-ASCHNER PHENOMENON)-ITS USE IN MEDICINE AND PSYCHOLOGY
}

\author{
AN EXPERIMENTAL AND COMPARATIVE STUDY OF GROUPS OF NORMAL \\ AND PATHOLOGIC SUBJECTS \\ SANTE NACCARATI, M.D., Sc.D. \\ NEW YORK
}

This phenomenon was first reported by Dagnini ${ }^{1}$ at the meeting of the Academy of Medical Sciences of Bologna, June 17, 1908. Four months later B. Aschner, ${ }^{2}$ unaware of the work of Dagnini, published a paper on the same subject. The reflex is called Aschner's reflex ordinarily, but in a spirit of fairness and justice to the Italian scientist, it should be identified primarily with the name of Dagnini.

The phenomenon consists in slowing of the radial pulse, lowering of the blood pressure and modification of the respiratory rhythm from compression of the eyeballs. Long before Dagnini and Aschner, Luciani had observed that stimulation of the branches of the trigeminal nerve with choloroform produced retardation of the heart; and Wagner von Jauregg used compression of the eyes to arouse stuporous patients. He did not explain the cause or the mechanism of the phenomenon.

Experiments on animals, carried out by Aschner, Miloslavich ${ }^{3}$ and others, showed that this was a real reflex having as the centripetal pathway the trigeminal nerve and as the centrifugal pathway the vagus. Aschner also demonstrated that the phenomenon could not be attributed to stimulation of the vagus by increased intracranial pressure.

Petzetakis $^{4}$ and more recently Fumarola and Mingazzini ${ }^{5}$ have shown that the centrifugal pathway of the oculocardiac reflex is constituted also, although in a lesser degree, by the sympathetic. By

1. Dagnini, G.: Intorno ad un riflesso provocato in alcuni emiplegici collo stimolo della cornea e colla pressione sul bulbo oculare, Boll. di scienze med., Bologna 8:380, 1908.

2. Aschner, B.: Ueber einen bisher noch nicht beschriebenen Reflex vom Auge auf Kreislauf und Atmung. Verschwinden des Radialispulces bei Druck auf das Auge (Vorläufige Mitteilung), Wien. klin. Wchnschr., No. 44:1529 (Oct. 29) 1908.

3. Miloslavich, E.: Ueber Trigeminus- Vagusreflexe, Wien, med. Wchnschr. 51:3051 (Dec. 17) 1910. Grossmann, J., and Miloslavich, E.: Ueber die Beeinflussung der Hertztätigkeit durch Bulbusdruck, Wien. klin. Rundschau 12: $177,1912$.

4. Petzetakis: Etude expérimentale sur les voies centrifuges du réflexe oculo-cardiaque, Compt. rend. Soc, de biol. 76:657 (April 25) 1914. Effets de la section de la moelle cervicale sur le rythme cardiaque, Arch. d. mal. du coeur 10:66 (Feb.) 1917.

5. Fumarola, G., and Mingazzini, E.: Contributo clinico e sperimentale allo studio del riflesso oculo-cardiaco, Policlinico, Rome 24:404 (Oct.) 1917. 
severing the cervical cord, the sympathetic connection with the medulla is interrupted and the centrifugal impulse traveling only through the vagal cardio-inhibitory fibers causes exaggeration of the reflex.

Since the appearance of Daginini's and Ascher's works a great number of papers have been published on this subject. Many reports have been contradictory and misleading and the inversion or exaggeration of the oculocardiac reflex was given too broad a significance.

The reflex has also been employed therapeutically in paroxysmal tachycardia (Lian, ${ }^{6}$ Voisin and Benhamou ${ }^{7}$ ) and in hiccough (Loeper and Weil $^{8}$ ).

It has been assumed by some authors that the normal reflex is retardation of the pulse five to twelve beats per minute. When the pulse is reduced more than twelve the reflex is called exaggerated. When the retardation does not surpass four, the reflex is abolished. When instead of retardation, acceleration occurs, the reflex is inverted. Others have proposed similar classifications but, as will be shown later, classifications of this sort are arbitrary and do not give the real individual value because the same subject may show at different times a normal, an inverted and an abolished reflex, or a normal, an abolished and an exaggerated reflex. Small wonder that the reports of different authors are so discordant. Only in regard to tabes do the reports agree, the reflex having quite generally been found abolished by Auer, ${ }^{9}$ Fumarola and Mingazzini, ${ }^{5}$ Gautrelet, ${ }^{10}$ Lesiur, Vernet and Petzetakis, ${ }^{11}$ Levine, ${ }^{12}$ Leeper and Mougeot, ${ }^{13}$ Orlandi, ${ }^{14}$ Santiago Barabine ${ }^{15}$ and by the writer.

6. Lian, C.: De l'emploi thérapeutique du réflexe oculo-cardiaque dans les crises tachycardiques, Arch. d. mal. du coeur. 8:193 (July) 1915.

7. Voisin, R, and Benhamou: La valeur thérapeutique du réflexe oculocardiaque, Paris méd. 9:210 (March 8) 1919.

8. Loeper and Weil: Action favorable de la compression oculaire sur certaines manifestations nerveuses et en particulier sur le hoquet, Bull. et mém. Soc. méd. đ. hôp. de Paris 37:631, 1914.

9. Auer, E. M.: The Oculocardiac Reflex in Syphilis of the Central Nervous System, J. A. M. A. 68:901 March 24) 1917.

10. Gautrelet, J.: Le réflexe oculo-cardiaque, Paris méd. 3:583, 1912.

11. Lesieur, Vernet and Petzetakis: Note sur l'abolition fréquente du réflexe oculo-cardiaque dans le tabes, Bull. et mém. Soc. méd. d, hôp. de Lyon 13:198 (March) 1914.

12. Levine, S. A.: The Oculocardiac Reflex. An Electrocardiographic Study with Special Reference to the Differences Between Right and Left Vagal and Ocular Pressure in Tabetics and Non-Tabetics, Arch. Int. Med. 15:758 (May 15) 1915.

13. Loeper, M., and Mougeot, A.: Absence fréquente du réflexe oculocardiaque dans le tabes, Bull. et mém. Soc. méd. d. hôp. de Par., Dec. 26, 1913, p. 942 ; Progrès méd., Dec. 27, 1913, p. 675.

14. Orlandi, N.: Sul valore clinco del riflesso oculo-cardiaco, Riforma med. 31:232, 260 and 288, 1915.

15. Santiago-Barabino, A.: Contribucion al estudio del reflejo óculocardiáco, Prensa med., Argentina, Buenos Aires, Nos. 29, 30, 31, 1917. 
To give a few examples of the conflicting results in general paresis, Lesieur, Vernet and Petzetakis usually found the oculocardiac reflex exaggerated, while Fumarola and Mingazzini, Roubinovitch and Régauld de la Sourdière, ${ }^{16}$ and Aguglia ${ }^{17}$ found it abolished. In epilepsy Lesieur, Vernet and Petzetakis, ${ }^{18}$ Aguglia, and Dufour and Legras ${ }^{19}$ reported exaggeration of the reflex, while Mallard and Cordet $^{20}$ did not find it exaggerated and rejected the explanation of Lesieur, Vernet and Petzetakis that bromids cause the reflex to be less accentuated. In my experiments, although there was found a definite relative tendency to vagotonic reaction among the group of fifty epileptic patients, the findings of Lesieur, Vernet and Petzetakis could not be substantiated. Fumarola and Mingazzini ${ }^{5}$ found in epileptics a tendency toward exaggeration. Orzechowski and Meisels ${ }^{21}$ studied a group of epileptic patients with pharmacodynamic tests and found that they gave a vagotonic reaction. In diphtheria Aviragnet, Dorlencourt and Bouttier ${ }^{22}$ found that of twenty-six patients the reflex was normal in 42.3 per cent. and abolished in 57.7 per cent., while Gunson, ${ }^{23}$ who examined fifty cases, found that the reflex was normal in 92 per cent. of the patients. In dementia praecox, Truelle and Bourdelique $^{24}$ found the reflex inverted or almost so. Roubinovitch

16. Roubinovitch and Sourdière, Regnauld de la: Le réflexe oculo-cardiaque dans les demences organiques, Soc. psych. de Par., June 18, 1914.

17. Aguglia, E.: Il riflesso oculo-cardiaco negli alienati di mente, Riv. ital. di neuropatol, psichiat. ed elettrater 7:385, 1914. I1 riflesso oculo-respiratorio negli alienati di mente, Ibid. 8:57, 1915.

18. Lesieur, Vernet and Petzetakis: Contribution à l'etude du réflexe oculocardiaque; son exagération dans l'epilepsie; ses variations sous l'influence d'actions médicamenteuses ou toxiques, Bull. et mém. Soc. méd. d. hôp. de Par. March 6, 1914; Considérations sur les modifications des reflexes produits par compression des globes oculaires chez certains epileptiques, Lyon méd. March 29, 1914, p. 721; Considérations physio-pathologiques sur un cas d'arrêt du coeur par le réflexe oculo-cardiaque chez un épileptique, Bull. et mém. Soc. med. d. hôp. de Par. 37:394 (March 6) 1914.

19. Dufour, H., and Legras, M.: Réflexe oculo-cardiaque provoquant l'arrêt du coeur, l'automatisme ventriculaire et la dissociation auriculoventriculaire; syndrome hypovarien et hyperthyroiden; crises épileptiformes; Bull. et mém. Soc. méd. d. hôp. de Par. 37:686 (April) 1914.

20. Maillard and Codet: Le réflexe oculo-cardiaque chez les epileptiques, Soc. de Psychiat. de Par., June 18, 1914.

21. Orzechowski, K., and Meisels, E.: Untersuchung über das Verhalten des vegetativen Nervensystems in der Epilepsie, Epilepsia, Leipzig 4:181 and 293, 1912-1913-1914.

22. Aviragnet, E. C.; Dorlencourt, H., and Bouttier, H.: Le réflexe oculocardiaque au cours de l'intoxication diphtérique, Compt. rend. Soc. de Biol., 76:771 (May) 1914. 1915.

23. Gunson, E. B.: The Oculo-Cardiac Reflex, Brit. J. Child. Dis. 12:97,

24. Truelle and Bouderlique: Le réflexe oculo-cardiaque dans la dèmence précoce des jeunes gens, Ann. méd. psychol. 7:389, 1916. 
and Regnauld de la Sourdière found the reflex abolished in 50 per cent. of their cases; in Graziani's report, 34 per cent. showed an abolished reflex, 48 per cent. a normal and 18 per cent. an inverted reflex. On the other hand, if we take the analysis of Gorriti, ${ }^{26}$ based on a much larger number (207 cases), the results are entirely different: 84 per cent. had a normal, 8 per cent. an inverted and 8 per cent. an abolished reflex. Evidently in any variability curve, gaps are filled when a larger number of cases is studied. The report of Aguglia ${ }^{17}$ on seventy-two insane cases, gave 60.8 per cent. as showing an exaggerated reflex, while the report of Gorriti, based on 721 mental cases, showed that the oculocardiac reflex was normal in 81 per cent., inverted in 10 per cent. and abolished in 8 per cent. The reasons for such discordant results are to be found, aside from the individual differences, in the diversity of methods and scales employed.

\section{ORIGINAL INVESTIGATIONS}

I undertook a series of observations on different groups of subjects, normal and pathologic, for the purpose of comparing groups instead of individuals. The pathologic cases included tabes, general paresis, psychoneuroses, thyroid states, feeblemindedness and a group of different organic nervous diseases. Most of these patients were taken from the Neurologic Institute, a few from the neurologic department of the Post-Graduate Medical School and Hospital, the feebleminded from Randall's Island, through the courtesy of the medical director, Dr. Vavasour. Seventy-five of the 165 normal subjects were students in the psychologic department of Columbia University, the other ninety were taken at random regardless of age, sex and occupation.

The technic for the induction of the oculocardiac reflex is simple. The subject is placed in the recumbent posture or sits comfortably in an armchair, the head lying on the back of the chair. $\mathrm{He}$ is allowed to rest until the pulse becomes quite regular and equal for the four quarters of a minute. Then with the thumb and index or middle finger of the right hand gentle pressure is exerted on the eyeballs through the closed lids. The experimenter stands at the subject's right, taking the pulse at the right wrist. In order to obtain better results, especially when the oculocardiac has to be taken at different times, it is advisable to use an instrument similar to one which I shall describe later.

25. Graziani, A.: Contributo allo Studio del sistema endocrino simpatico in alcune psicosi, Riv. ital. di neuropatol., psichiat. ed elettroter. 12: Nos. 2 and 3 (Feb.-March) 1919.

26. Gorriti, F.: El reflejo oculo-cardíaco en 721 enfermos mentales, Semana méd. 23:671 (Dec. 28) 1916. 
In taking the oculocardiac reflex it is better to divide the pulsations into four periods of 15 seconds each. In this way one can easily stop whenever tenderness, or increased sensitiveness or a sharp fall of blood pressure appears and at the same time obtain the average for a minute. This method also gives a measure of the regularity of the oculocardiac reflex. Tabetic patients show no or slight variability in the four quarters of a minute whereas psychoneurotics show the greatest fluctuations; for instance, a psychoneurotic gives this response: pulse : $25,26,23,24$, total 98 ; oculocardiac reflex : $23,26,28,27$, total 104. A tabetic patient will give this response: pulse: $22,22,22,22$, total 88 ; or $22,22,22,23$, total 89 ; oculocardiac reflex, $22,22,22,22$, total 88 ; or $23,22,22,22$; total 89 .

The existence of such great variations in the same person at different times shows the fallacy of designating the reflex by such adjectives as normal, normal feeble, normal medium, normal strong, exaggerated, inverted, when this designation is intended for diagnostic purposes. Moreover, the term "inverted" includes in the same category persons having an oculocardiac reflex from -1 to -20 or more; and the term "exaggerated" includes an oculocardiac reflex from +13 upward. Undoubtedly, the significance-physiologic, pathologic or psychologicof an oculocardiac reflex of -1 and -20 or +13 and +60 must be quite different. Therefore, I suggest that the difference in one minute between the pulse rate without ocular pressure and the pulse rate with pressure be always indicated in full with a positive or a negative sign. This algebraic difference should be called reflex index (R. I.). The pulse rate should also be given, as the value of a reflex index is not absolutely the same in a bradycardiac as in a tachycardiac.

Two of the women on whom the experiment was performed-one a neurotic, the other a normal subject-fainted during the experiment; in three other cases the operation had to be stopped because of threatening arrest of the heart. In four epileptic patients pressure of the ocular bulbs caused a seizure.

Five hundred and one subjects were observed, 165 normal and 336 pathologic.

\section{REFLEX INDEX IN NORMAL PERSONS}

In Table 1 of my report three groups of normal subjects arereported, a total of 100 persons.

Section A contains fifty university students (male). Of these:

2 or 4 per cent. had a reflex index of 0

14 or 28 per cent. had a reflex index of 1,2 (positive and negative)

13 or 26 per cent. had a reflex index of $3,4,5$ (positive and negative)

12 or 24 per cent. had a reflex index of $6,7,8$ (positive and negative)

5 or 10 per cent. had a reflex index of $9,10,11$ (positive and negative)

4 or 8 per cent. had a reflex index of 12 or more (positive and negative)* 
Section B contains twenty-five students (female). Of these:

1 or 4 per cent. had a reflex index of 0

3 or 12 per cent. had a reflex index of 1,2 (positive and negative)

9 or 36 per cent. had a reflex index of $3,4,5$ (positive and negative)

8 or 32 per cent. had a reflex index of $6,7,8$ (positive and negative)

2 or 8 per cent. had a reflex index of $9,10,11$ (positive and negative)

2 or 8 per cent. had a reflex index of 12 and more (positive and negative)

Section $C$ contains twenty-five male adults taken at random. Of these:

2 or 8 per cent. had a reflex index of 0

5 or 20 per cent. had a reflex index of 1,2 (positive and negative)

7 or 28 per cent. had a reflex index of $3,4,5$ (positive and negative)

6 or 24 per cent. had a reflex index of $6,7,8$ (positive and negative)

1 or 4 per cent. had a reflex index of $9,10,11$ (positive and negative)

4 or 16 per cent. had a reflex index of 12 or more (positive and negative),

If we were to classify the oculocardiac reflex as normal when the reflex index is from +5 to +12 , as abolished when the index is from 0 to +4 , as inverted when the index is negative, and as exaggerated when the index is above +12 , the whole group of these 100 ; normal subjects would show:

In 35 per cent. an abolished reflex

In 33 per cent. a normal reflex

In 9 per cent. an exaggerated reflex

In 23 per cent. an inverted reflex

This group would look quite pathologic to those who expect to find an index of from +5 to +12 in normal subjects. Even more pathologic would appear the normal subjects of Table 2, if the same criteria were applied for classification of the oculocardiac reflex. In fact, we would have found the first time:

26 or 40.0 per cent. with an abolished reflex

13 or 20.0 per cent. with a normal reflex

9 or 13.8 per cent. with an exaggerated reflex

17 or 26.1 per cent. with an inverted reflex

And the second time:

36 or 55.6 per cent. with an abolished reflex

9 or 13.8 per cent. with a normal reflex

4 or 6.1 per cent. with an exaggerated reflex

16 or 24.6 per cent. with an inverted reflex

These figures give sufficient ground for rejecting any classification of the reflex index of the kinds that have been so widely accepted. Continuing in the analysis of Table 2 , which includes sixty-five normal persons taken at random, whose oculocardiac reflexes were tested two or more times after an interval of from fifteen to ninety days, we found in the first test:

6 or $9.2 \%$ with a reflex index of 0

15 or $23.1 \%$ with a reflex index of 1,2 (negative or positive)

17 or $26.1 \%$ with a reflex index of $3,4,5$ (negative or positive)

13 or $20.0 \%$ with a reflex index of $6,7,8$ (negative or positive)

3 or $4.6 \%$ with a reflex index of $9,10,11$ (negative or positive)

11 or $16.9 \%$ with a reflex index of 12 and more (negative or positive), 
In the second test:

11 or $16.9 \%$ with a reflex index of 0

22 or $33.8 \%$ with a reflex index of 1,2 (positive and negative)

14 or $21.5 \%$ with a reflex index of $3,4,5$ (positive and negative)

10 or $15.4 \%$ with a reflex index of $6,7,8$ (positive and negative)

3 or $4.6 \%$ with a reflex index of $9,10,11$ (positive and negative)

5 or $7.7 \%$ with a reflex index of 12 and more (positive and negative)

and in the third test, given to thirty persons, we find:

4 or $13.3 \%$ with a reflex index of 0

12 or $40.0 \%$ with a reflex index of 1,2 (positive and negative)

9 or $30.0 \%$ with a reflex index of $3,4,5$ (positive and negative)

3 or $10.0 \%$ with a reflex index of $6,7,8$ (positive and negative)

0 or $0.0 \%$ with a reflex index of $9,10,11$

2 or $6.6 \%$ with a reflex index of 12 and more (positive and negative)

Again in the first test we found:

6 or $9.2 \%$ with a reflex index of 0

42 or $64.6 \%$ with a positive reflex index

17 or $26.1 \%$ with a negative reflex index

and in the second test :

11 or $16.9 \%$ with a reflex index of 0

38 or $58.4 \%$ with a positive reflex index

16 or $24.6 \%$ with a negative reflex index

In regard to the variations found in the same person in Table 2:

9 or 13.8 per cent. kept the same sign

8 or 11.2 per cent. showed a difference from -1 to +1

3 or 4.6 per cent. showed a difference from -2 to +2

3 or 4.6 per cent. showed a difference from -3 to +3

6 or 9.2 per cent. showed a difference from -4 to +4

6 or 9.2 per cent. showed a difference from -5 to +5

2 or 3.1 per cent. showed a difference from -6 to +6

3 or 4.6 per cent. showed a difference from -7 to +7

25 or 38.5 per cent. showed a difference from \pm 8 and more

The average index of the following subjects, who were tested from four to six times, gives an idea of the variability of a single index from the average.

In Case 3, 6 tests yielded an average index of 4.83

In Case 7,4 tests yielded an average index of 2.5

In Case 13, 4 tests yielded an average index of 5.5

In Case 14, 4 tests yielded an average index of 11.25

In Case 15, 6 tests yielded an average index of 1.1

In Case 19, 4 tests yielded an average index of 2.25

In Case 26, 4 tests yielded an average index of -1.0

In Case 28, 4 tests yielded an average index of -0.5

In Case 29, 4 tests yielded an average index of 1.75

In Case 30, 4 tests yielded an average index of 4.5

In Case 44, 5 tests yielded an average index of 1.2

In Case 45, 6 tests yielded an average index of 1.0

In Case 50, 4 tests yielded an average index of -4.5

In Case 56, 4 tests yielded an average index of 4.5 
This demonstrates how important it is to have the averages obtained from many trials.

In the absence of the ordinary statistic treatment of the tables reported, a measure of the number of times that each reflex index appeared amongst the normal subjects examined seems necessary before closing the report on Tables 1 and 2 .

In the following tabulated summary the reflex indexes are given from 1 to more than 12 with their frequency as encountered in Tables 1 and 2 (first and second trials separately) and finally the frequency in all 230 tests.

It appears from this that the positive indexes are encountered about three times more frequently than the negative ones, and that the small indexes, 1 to 4 and 0 , are the most frequent. The positive indexes from 1 to 4 and 0 indexes in the 230 tests constitute 41.3 per cent. of the whole group. This fact demonstrates once more that the so-called abolished reflex (reflex index from 0 to +4 ), is more frequently encountered in normal persons and therefore it cannot be considered pathologic.

Reflex Indexes from 1 to More Than 12, with Their Frequency as ENCOUNTERed in Tables 1 and 2 and the Frequency of THE Two Hundred AND ThIRTY Tests

\begin{tabular}{|c|c|c|c|c|c|c|c|c|}
\hline \multirow[t]{2}{*}{ R. I. } & \multicolumn{2}{|c|}{$\underset{5}{\text { Table } 1}$} & \multicolumn{2}{|c|}{$\begin{array}{c}\text { Table 2 } \\
\text { (First Test) } \\
6\end{array}$} & \multicolumn{2}{|c|}{$\begin{array}{c}\text { Table 2 } \\
\text { (Second Test) } \\
11\end{array}$} & \multicolumn{2}{|c|}{$\begin{array}{c}\text { Total of } 230 \\
\text { Tests } \\
22\end{array}$} \\
\hline & Positive & Negative & Positive & Negative & Positive & Negative & Positive & Negative \\
\hline $\begin{array}{r}1 \\
2 \\
3 \\
4 \\
5 \\
6 \\
7 \\
8 \\
9 \\
10 \\
11 \\
12 \\
13 \text { and more }\end{array}$ & $\begin{array}{r}6 \\
8 \\
4 \\
12 \\
9 \\
6 \\
3 \\
9 \\
1 \\
5 \\
1 \\
0 \\
8\end{array}$ & $\begin{array}{l}4 \\
4 \\
1 \\
1 \\
2 \\
3 \\
1 \\
4 \\
0 \\
1 \\
0 \\
2 \\
0\end{array}$ & $\begin{array}{r}7 \\
3 \\
4 \\
5 \\
2 \\
6 \\
2 \\
0 \\
0 \\
1 \\
1 \\
1 \\
10\end{array}$ & $\begin{array}{l}3 \\
2 \\
1 \\
5 \\
0 \\
1 \\
2 \\
2 \\
0 \\
1 \\
0 \\
0 \\
0\end{array}$ & $\begin{array}{l}6 \\
9 \\
6 \\
3 \\
2 \\
4 \\
1 \\
1 \\
0 \\
0 \\
3 \\
0 \\
0 \\
4\end{array}$ & $\begin{array}{l}5 \\
2 \\
2 \\
1 \\
0 \\
4 \\
1 \\
0 \\
0 \\
0 \\
0 \\
0 \\
1\end{array}$ & $\begin{array}{r}19 \\
20 \\
14 \\
20 \\
13 \\
16 \\
6 \\
9 \\
1 \\
9 \\
2 \\
1 \\
22\end{array}$ & $\begin{array}{r}12 \\
8 \\
4 \\
7 \\
2 \\
8 \\
4 \\
6 \\
0 \\
2 \\
0 \\
2 \\
1\end{array}$ \\
\hline Total & 72 & 23 & 42 & 17 & 38 & 16 & 152 & 56 \\
\hline
\end{tabular}

REFLEX INDEX IN PSYCHONEUROTIC AND FEEBLEMINDED PERSONS

A contrast of the findings of the normal subjects of Tables 1 and 2 with those Tables 3 and 4 , which include, respectively, psychoneurotic and feebleminded persons, does not reveal much.

In Table 3 :

7 or 9.3 per cent. had a reflex index of 0

17 or 22.6 per cent. had a reflex index of 1,2 , positive or negative

16 or 21.3 per cent. had a reflex index of $3,4,5$, positive or negative

17 or 22.6 per cent. had a reflex index of $6,7,8$, positive or negative

7 or 9.3 per cent. had a reflex index of $9,10,11$, positive or negative

11 or 14.6 per cent. had a reflex index of 12 and more 
In Table 4:

3 or 6 per cent. had a reflex index of 0

12 or 24 per cent. had a reflex index of 1,2 , positive or negative

15 or 30 per cent. had a reflex index of $3,4,5$, positive or negative

7 or 14 per cent. had a reflex index of $6,7,8$, positive or negative

8 or 16 per cent. had a reflex index of $9,10,11$, positive or negative

5 or 10 per cent. had a reflex index of 12 and more

If we classify the subjects of these two groups by the criteria used for the normal subjects, we do not find much difference, or rather these two groups look more normal than groups of Tables 1 and 2 .

In fact, in Table 3 :

In 27 or 36.0 per cent. the reflex is abolished

In 25 or 33.3 per cent. the reflex is normal

In 5 or 6.7 per cent. the reflex is exaggerated

In 18 or 24.0 per cent. the reflex is inverted

and in Table 4:

In 18 or 36 per cent. the reflex is abolished

In 21 or 42 per cent. the reflex is normal

In 4 or 8 per cent. the reflex is exaggerated

In 7 or 14 per cent. the reflex is inverted

The data of Table 4 do not agree with the report of Aguglia, ${ }^{17}$ who found the oculocardiac reflex most exaggerated in phrenasthenics. A difference is found in comparing the normal groups (Tables 1 and 2) with Table 8 , which includes patients taken at random from the clinic suffering from organic nervous diseases. There is a larger number of cases with a 0 index in Table 8.

In Table 8 we find:

11 or 22 per cent. with a reflex index of 0

7 or 14 per cent. with a reflex index of 1,2 , positive and negative

15 or 30 per cent. with a reflex index of $3,4,5$, positive and negative

7 or 14 per cent. with a reflex index of $6,7,8$, positive and negative

6 or 12 per cent. with a reflex index of $9,10,11$, positive and negative

4 or 8 per cent. with a reflex index of 12 and more, positive and negative

However, it must be remembered that among the organic cases also the reflex index is inconstant.

If these cases are classified into abolished, normal, exaggerated and inverted, as has been done with other groups, their distribution will not differ, to any sensible extent, from that found in classifying the results in sixty-five normal persons taken at random.

Here we have:

26 or 52 per cent. with an abolished reflex

13 or 26 per cent. with a normal reflex

4 or 8 per cent. with an exaggerated reflex

7 or 14 per cent. with an inverted reflex 
REFLEX INDEX IN THYROID DISEASE

Omitting the cases of exophthalmic goiter in which the secretory alterations are qualitative rather than quantitative, the remainder of this group is constituted of thirty-four hyperthyroid and twenty hypothyroid cases.

Of the hyperthyroid cases

3 or 8.8 per cent. had a reflex index of 0

10 or 29.4 per cent. had a reflex index of 1,2 , positive and negative

4 or 11.7 per cent. had a reflex index of $3,4,5$, positive and negative

8 or 23.5 per cent. had a reflex index of $6,7,8$, positive and negative

0 or 0.0 per cent. had a reflex index of $9,10,11$, positive and negative

9 or 26.5 per cent. had a reflex index of 12 or more, positive and negative

20 or 58.9 per cent. had a negative or 0 reflex index

14 or 41.1 per cent. had a positive reflex index

Of the hypothyroid cases

0 or 0 per cent. had a reflex index of 0

1 or 5 per cent. had a reflex index of 1,2 , positive or negative

4 or 20 per cent. had a reflex index of $3,4,5$, positive or negative

2 or 10 per cent. had a reflex index of $6,7,8$, positive or negative

4 or 20 per cent. had a reflex index of $9,10,11$, positive or negative

9 or 45 per cent. had a reflex index of 12 or more

2 or 10 per cent. had a negative or 0 reflex index

18 or 90 per cent. had a positive reflex index

In this table and in Tables 6 and 7 , in which more than one reflex index are given for one subject, the first was computed.

It was observed in many instances that the same subject showed a positive and a negative or 0 index at different times. Although a sharp distinction of the hyperthyroid and hypothyroid cases in sympathicotonic and vagotonic patient (Eppinger and Hess ${ }^{27}$ ) cannot be drawn, it clearly appears from this table that the hyperthyroid patients tend to react as sympathicotonic and the hypothyroid patients as vagotonic. This fact may help somewhat in the diagnosis of the thyroid states. My results agree with those of Petzetakis, ${ }^{28}$ Blanc, ${ }^{29}$ and Garnier and Lévi-Franckel. ${ }^{30}$ In several hypothyroid patients when large

27. Eppinger, H., and Hess, L.: Pathologie des vegetativen Nervensystems, Ztschr. f. klin. Med. 68: 1919; Die Vagototonie, Eine klinische Studie, Berlin, 1910.

28. Petzetakis: Le reflexe oculo-cardiaque dans le syndrome hypothiroïdien, Presse méd. 25:12 (Jan. 8) 1917.

29. Blanc, J.: La dysthroidie facteur de névrose. Le réflexe oculo-cardiaque régulateur de l'opethérapie thyrodienne, Progès méd. 32:95 (March 24) 1917.

30. Garnier and Lévi-Franckel: Modifications du réflexe oculocardiaque sous l'influence de la gestation, Bull. et mém. Soc. méd. d. hôp. de Par. 37:252 (July 24) 1914; Le réflexe oculo-cardiaque dans la grossesse, Compt. rend Soc. de biol. 76:645 (April) 1914. 
doses of thyroid extract were administered, the reflex index became smaller, sometimes even negative.

\section{REFLEX INDEX IN EPILEPSY}

On the patient in Case 47, suffering from jacksonian epilepsy, craniectomy was performed. Previous to the operation the reflex was $107-73=+34$. Eleven months later the patient had a relapse, this time showing an epileptic equivalent. At this time the reflex index was +16 .

Case 46 was also a case of jacksonian epilepsy; the patient was operated on. The two reflexes were taken five days apart, before and after the operation.

The assumption that bromids check the exaggeration of the oculocardiac reflex has not been proved in my cases. Subjects such as Case 11 showed a reflex index of +19 when taking bromids and +9 when not taking them; the patient in Case 2 had a reflex index +9 when taking bromids and +3 and -1 when not taking them; the reflex index of the patients in Cases 25,27 and 50, who were taking bromids, were respectively $+13,+31,+13$, while those of the patients in Cases 3,17, 18, 20, 22 and 28, who were not taking bromids, were $0 .-5 ;-2,-1,-4 ;-2 ;-1 ; 0$ and 0 . The patient in Case 43 had a reflex index of -4 when taking bromids and -7 when not taking them. In Case 1 the reflex index was negative with and without bromids. Here also great variations were found in the reflex index when the oculocardiac reflex was taken at different dates. In general, it must be admitted that, despite the variations and the individual differences, the epileptic patients tend to react with a large positive index. The fact that not all epileptic patients are vagotonic demonstrates once more that epilepsy as a clinical entity does not exist; the convulsive seizure is the expression of entirely different pathologic conditions and etiologic factors.

In classifying the subjects of Table 6 we find:

4 or 8 per cent. with a reflex index of 0

10 or 20 per cent. with a reflex index of 1,2 , positive or negative

10 or 20 per cent. with a reflex index of $3,4,5$, positive or negative

6 or 12 per cent. with a reflex index of $6,7,8$, positive or negative

4 or 8 per cent. with a reflex index of $9,10,11$, positive or negative

16 or 32 per cent. with a reflex of 12 or more, positive or negative

The average indexes obtained from the algebraic sum of the reflex index of this and of the other tables show that the epileptic and the hypothyroid patients have the largest average index, namely, +7.48 and +11.95 , respectively. The smallest average index was found among the tabetic patients $(+1.23)$. 
REFLEX INDEX IN TABES AND GENERAL PARESIS

Thirty cases of tabes and twenty cases of general paresis are reported in Table 7 . What differentiates these subjects, especially the tabetic patients, from all the others, is the small index, even when the oculocardiac reflex is repeated.

Of thirty tabetic patients, we find that in

8 or 26.6 per cent. the reflex index was 0

13 or 43.4 per cent. the reflex index was 1

5 or 16.6 per cent. the reflex index was 2

1 or 3.3 per cent. the reflex index was 3

3 or 10.0 per cent. the reflex index was 4 or more

And of twenty general paresis patients, we find that in

3 or 15 per cent. the refiex index was 0

6 or 30 per cent. the reflex index was 1

6 or 30 per cent. the reflex index was 2

1 or 5 per cent. the reflex index was 3

4 or 20 per cent. the reflex index was 4 or more

20 or 66.6 per cent. of the tabetic patients had a positive index

2 or 6.6 per cent. of the tabetic patients had a negative index

11 or 55.0 per cent. of the general paresis patients had a positive index

6 or 30.0 per cent. of the general paresis patients had a negative index

When the reflex was taken twice or more, the index did not constantly keep the same sign. Only in one case (general paresis) was the index greater than 12 .

The absence of oculocardiac reflex in tabes and cerebrospinal syphilis has been attributed to bulbar lesions; to early involvement of the anastomotic fibers running from the fifth to the tenth cranial nerves in the medulla oblongata which have been described by Van Gehuchten and by Ramón y Cajal. If this were true, then we should find bulbar symptoms in all the cases of cerebrospinal syphilis showing a 0 or small index, because we could not imagine a lesion of the anastomotic fibers from the fifth to the tenth cranial nerves which would not sooner or later involve the surrounding fibers. Moreover, in cases of bulbar lesions the oculocardiac reflex has not been shown to be absent, as Guillain and Dubois ${ }^{31}$ have pointed out. These authors think that the oculocardiac reflex may serve to differentiate bulbar paralysis from the pseudobulbar. In several cases of bulbar paralysis that I have observed the oculocardiac reflex was not found absent all the time. Of course it will be absent when the center of the reflex arc is involved. It seems more probable that only in a small proportion of the cases of tabes, general paresis and cerebro-

31. Guillain, G., and Dubois, J.: L'abolition et l'inversion du réflexe oculocardiaque dans les paralysies pseudo-bulbaires, Bull. et mém. Soc. méd. d. hôp. de Par. 37:584 (March) 1914. 
spinal syphilis the absence of the oculocardiac reflex is due to a reflex lesion in the center; most cases of so-called absence of the oculocardiac reflex are due to peripheral lesions, when they are not due to constitutional factors.

Undoubtedly the syphilitic virus exerts a selectivs action on both subdivisions of the autonomic system, and when the receptors or the effectors are involved in the lesion, the reflex cannot take place or it will take place in an altered manner. The early digestive, sexual, secretory, and circulatory disorders, the changes in moods and in the affective and emotional life, which are observed in tabes, general paresis and cerebrospinal syphilis before the gross organic signs appear, are indications of the early involvement of the autonomic system. When the autonomic system is functionally affected, as in psychoneurotic patients, we find also cenesthetic, and similar functional signs suggestive of the unharmonious correlation between the two subdivisions of the autonomic system, such as myosis, enophthalmos and reduction of the palpebral fissures in some cases ; mydriasis, exophthalmos and widening of the palpebral fissures in others. The conclusion which can be drawn from this consideration is that the oculocardiac reflex, when accurately studied in each person, may give useful information on the condition of the autonomic system and may thus help in the study of the personality.

It is obvious that from the clinical standpoint the oculocardiac reflex cannot constitute a positive diagnostic sign, which could compete with the other well defined and constant symptoms and laboratory findings of tabes. In the early stages of tabes, general paresis and cerebrospinal syphilis, the oculocardiac reflex could serve for differential diagnosis from functional nervous diseases, but the frequency with which the 0 or the small reflex index is encountered in normal persons renders this sign doubtful and unreliable.

FACTORS RESPONSIBLE FOR INDIVIDUAL DIFFERENCES AND VARIATIONS

The factors responsible for the individual differences and variations in the oculocardiac reflex are: (1) age, (2) sex, (3) position of the subject during the experiment, (4) amount of pressure exerted on the eyeballs, (5) physiologic state, (6) physical condition, (7) psychic conditions, and (8) internal or constitutional factors. By internal factors is meant mainly the makeup of the sympathetic endocrine system, which differs greatly among individuals. Broadly speaking, this system forms a large part of what is included in the old terminology of constitution, character and temperament. Besides its relations to other important vital functions, this system is at the basis of cenesthesia. The physical condition is indicated by the development, nutrition, 
strength, etc., and in general by the state of health of the subject. The physiologic state includes such functions as digestion, fatigue, the action of drugs, etc., and menstruation or pregnancy in women. The other items do not require explanation.

Factors 1,2 and 3 can be equalized easily.

Factor 4, which seemed to play a great rôle in the differences and variations found in the same person or in different persons, was eliminated with a simple device consisting of a small instrument resembling a lever having the fulcrum at the center and the power at the ends. The fulcrum was laid on the nose of the subject like spectacles whose lenses were substituted by two light wooden spoons protected with cotton, which could be moved toward the eyeballs with a gentle pressure. The pressure was applied with an ordinary sphygmomanometer having a long bag and a long band so that it could be wrapped around the head of the subject, covering the eyes. The reading in millimeters of mercury indicated the amount of pressure that was used for all subjects submitted to different tests. This method eliminated the errors that may occur when pressure is applied with the fingers. Roubinovitch ${ }^{32}$ has devised a similar apparatus, but he did not use the sphygmomanometer reading.

Factors 5 and 6 can be roughly equalized if a careful selection is made of subjects homogeneous as regards their physical and physiologic state.

Factors 7 and 8 cannot be equalized. Here the oculocardiac reflex may be of use. It may constitute an index of the psychic condition and of the sympathetic-endocrine makeup of the subjects, but only when the other factors have been standardized. In normal persons the reflex index may serve as an indication of reflex control, moods, courage, emotions, etc., traits whose scales are wanting. The different behavior of persons when confronted with the same situation is well known. Vague terms, such as temperament, character and neurotic constitution are used to explain why some persons are so abnormally self-conscious as to reach the degree of erythrophobia, why they cannot speak in public without showing a flushed face and having tachycardia, why they cannot undertake or meet a dangerous situation without trembling; whereas others never blush, meet crowds, without any

32. Roubinovitch, J., and de la Sourdière, Regnauld: Le réflexe oculocardiaque dans les hémiplégies et les diplegies cérebrales, Bull et mém. Soc. méd. d. hôp. de Par. 37:909, 1914; Compresseur oculaire pour la recherche du réffere oculocardiaque, Comp. rend Acad. d. sc. Par. 163:137, 1916; Progrès méd. 35: 367 (Aug. 21) 1920. In the latter article the author describes a manometric oculocompressor which is a modification of the one he originated in 1916. When my paper was submitted for publication I did not know that such a modification was being meditated. 
sign of anxiety and brave dangers without trembling. The answers to these questions have not yet been given, but it can be said without fear of contradiction that many doubts will be cleared up when a better knowledge of the autonomic system is obtained. For the study of this system, the Dagnini-Aschner reflex and probably also the HerringKratschmer reflex may give useful information. In order to obtain information of practical value, however, psychologic methods must be employed first on a large number of normal subjects before passing to the abnormal.

In Table 1, height and weight are given. These measurements, together with other minute anthropometric data not given, were taken in order to learn whether any correlation exists between the morphologic type of subject and the oculocardiac reflex. It seemed to the writer that subjects having small positive, or a 0 or a negative index were more intelligent than those who had a larger positive index. An intelligence test (Otis, form $A$ and Alpha) was given to forty persons of group A (Table 1). Realizing the inconstancy of the reflex index, the results of these correlations cannot be taken at face value. When the average of the indexes, based on many tests, are obtained, the correlation between the average index and the intelligence, and between the average index and the morphologic type, will form the subject of another paper.

INFLUENCE OF CRANIAL NERVES ON REFLEX INDEX

Before concluding I shall report what seems to be an experimental and clinical confirmation of the experiments of Aschner on animals. In order to find what cranial nerves have an influence on the oculocardiac reflex, a group of patients presenting unilateral complete peripheral paralysis of cranial nerves was selected. The oculocardiac reflex was tested at different times on one case each of paralysis of the third, fourth, fifth (motor branch) cranial nerves; fifth (sensory branch) sixth, ninth, eleventh and twelfth cranial nerves; on three cases of second and on eight cases of seventh cranial nerve paralysis. No case of eighth and tenth cranial nerve paralysis was available. In a case of diphtheric polyneuritis, in which both vagus nerves were involved, the index was found to be very large. The patient, a woma. 27 years of age, showed left facial paralysis, absolute pupillary rigidity, paresis of the muscles of respiration which kept the patient in severe danger of death for several days, bilateral paralysis of the velum palati, disturbance of deglutition, and laryngeal paralysis. The first time the oculocardiac reflex was $112-64=+48$; three days later it was $130-58=+72$. As there was danger of arrest of the heart and of respiratory paralysis, the reflex was not repeated again until four weeks later when the patient's recovery was assured. The reflex 
index at that time was between +6 and +12 . Collet and Petzetakis, ${ }^{33}$ in five cases of traumatic vagus lesion, found the reflex inverted. In the case referred to in the foregoing it must be supposed that the thoracic or inferior cardiac branches of the vagus nerves were intact, while the cardiac sympathetic branches were affected, causing the reflex to discharge itself through the vagus alone with production of marked bradycardia.

In the cases of second, third, fourth (motor), fifth, sixth, seventh, ninth, eleventh and twelfth nerve paralysis, no substantial differences were found between the reflex of the left eye and the right eye. The: difference was never above 2 counts negative or positive.

In three cases of Bernard-Horner syndrome, differences of a few counts between the right and left index were found. Probably the: differences would have been larger if the lesion of the cervical sympathetic nerve had been complete.

The most important observation was made on a patient suffering from "tic douloureux," who was operated on by Dr. Taylor at the Neurologic Institute for posterior root resection of the right trigeminal nerve. After the operation the reflex of both eyes was taken. four times, once every second day. The pulse rate is given for quarters of a minute. The findings of the first examination were: $27,27,27,27$, average 108 ; oculocardiac reflex, right, $27,27,27,27$, average 108 ; left, $26,25,26,25$, average 102 . The findings of the second examination were: pulse $18,17,17,17$, average 69 ; oculocardiac reflex, right, $17,17,17,17$, average, 68 ; left, $15,15,15,15$, average 60 . The findings of the third examination were: pulse 19, $20,21,21$, average 81 ; oculocardiac reflex, right, $20,19,20,21$, average80 ; oculocardiac reflex, right, $20,19,20,21$, average $80 ;$ left, 18 , $18,18,18$, average 72 . The findings of the fourth examination were: pulse, 23, 21, 20, 20, average 84 ; oculocardiac reflex, right, 22, 21, 21,20 , average 84 ; left, $20,18,18,19$, average 75 .

\section{INFLUENCE OF PAIN STIMULATION ON REFLEX INDEX}

Pain stimulation with heavy pressure on the mandible, maxilla and eyebrow gave these results in three trials : left mandible, 20, 21, 21, 21 , average 83 ; left maxilla, 21, 21, 21, 22, average, 85 ; left eyebrow, 20 , $20,21,21$, average 82 ; right mandible, $20,20,21,21$, average 82 ; right maxilla, $20,21,22,20$, average 83 ; right eyebrow, $20,21,21$, 21 , average, 83 .

This experiment was tried in order to exclude the possibility that

33. Collet and Petzetakis: Le réflexe oculo-cardiaque dans les lésions: traumatiques des pneumogastriques, Compt. rend. Soc. de biol. 79:1147 (Dec.. 16) 1916. 
the slowing down of the pulse rate, obtained by compression of the right eye, was merely a pain response, which could not take place on the right on account of anesthesia. The same experiment was tried on thirty normal subjects (Table 2) and on thirty pathologic subjects, but no changes in the pulse rate similar to that obtained through ocular compression were found. This experiment proves that the oculocardiac reflex is not a response to pain stimulation; while the case of section of the fifth cranial nerve confirms the existence of a real reflex as described by Dagnini and Aschner. In this case the reflex could not be obtained on account of interruption of the centripetal pathway.

\section{SUMMARY}

1. The oculocardiac reflex is subject to individual differences and variations, as is the pulse.

2. Since normal persons are subject to the same changes in their oculocardiac reflex that have been found in many pathologic conditions, the oculocardiac reflex cannot constitute a positive sign for differential diagnosis. It may serve only as an indicator of probability.

3 . The classification of the oculocardiac reflex into normal, abolished, inverted and exaggerated classes cannot be accepted on account of the extreme inconstancy of the reflex index: the same normal or abnormal subject may present a positive, a negative, and a 0 index at different times, even when the hour, position, and the amount of ocular compression are kept constant.

About 40 per cent. of the normal subjects examined by the writer showed a reflex index of from 0 to +4 .

4. For clinical and psychologic purposes, the algebraic difference between the pulse rate without ocular compression and the pulse rate during the ocular compression should be given instead of such terms as normal, abolished, inverted and exaggerated. The algebraic difference should be termed the index of the oculocardiac reflex.

5. No scale of the oculocardiac reflex can be reliable which is not expressed in terms of averages. No value can be attributed to an index obtained at a single test. To measure a variable fact, such as the oculocardiac reflex, many measurements are necessary. Therefore the reflex index of a normal or pathologic person should be obtained only from the average of several tests taken at different times. Slight deviations of a few counts above or below the average index should not be given a pathologic significance. Large deviations from the reflex index, although likely to be found in normal states and in normal subjects, may indicate abnormal conditions of physiologic or psychologic states and may also be the expression of pathologic states. 
6. In psychology the oculocardiac reflex may be of use for the study of some traits the scales of which are lacking, if a large number of cases and proper methods are used.

7. My researches on pathologic cases have shown that in tabes the reflex index is 0 or very small; exceptionally it surpasses three units; it shows slight variations or no variations at all when taken taken at different times.

In general paresis the index tends to remain small, but cases showing a larger positive or negative index are encountered with much more frequency than in tabes.

In the feebleminded no tendency to a large positive index (exaggerated reflex) was found, as reported by some authors. The groups of psychoneurotic persons, feebleminded persons and persons with organic nervous diseases did not show any substantial variations that could not be found in a group of normal subjects.

In epilepsy, although a well defined tendency toward a large positive index (vagotonic reaction) was found, it was not the rule; cases with small positive indexes, with 0 and negative indexes, were quite often encountered. Bromids did not reduce the reflex index. Large variations from positive to negative indexes were found in the same person at different times.

In thyroid states, a definite tendency was found on the part of the hypothyroid patients to react with a positive index and of the hyperthyroid patients to react with a negative index; this tendency was much more definite in hypothyroid patients. Where the reflex could be repeated at different intervals, large variations were found. Administration of thyroid extract to the hypothyroid patient seemed to produce a reduction of the index.

8. In normal and pathologic cases, pressure over different sensitive spots of the body did not induce the changes in the pulse rate that were obtained with ocular compression.

9. Unilateral paralysis of the second, third, fourth, fifth (motor branch), sixth, seventh, ninth, eleventh, and twelfth cranial nerves did not modify the reflex to a substantial extent. Involvement of the vagus nerves greatly influenced the reflex index; involvement of the cervical sympathetic nerve caused a slight alteration of the index. Resection of the sensory branch of the trigeminal nerve produced suppression of the reflex on the side of the lesion, without influencing the reflex index of the other side. These facts substantiate the results of experiments previously reported, namely, that the centripetal pathway of the oculocardiac reflex is constituted exclusively by the sensory branch of the trigeminal nerve and that the centrifugal pathway is constituted mainly by the vagus and partially by the sympathetic nerve.

37 West Fifty-Fourth Street. 